\title{
Comunidades quilombolas e o Programa Nacional de Habitação Rural
}

\section{The quilombola communities and the National Rural Housing Program}

André Augusto Brandão - Doutor em Ciências Sociais. Professor do Programa de Estudos Pós-Graduados em Política Social da Universidade Federal Fluminense. Diretor adjunto do DATAUFF. E-mail: andre_brandao@id.uff.br

Salete Da Dalt - Doutora em Política Social pela Universidade Federal Fluminense. Coordenadora do DATAUFF. Diretora do IPPECET. E-mail: salete@datauff.uff.br

Sidimara Cristina de Souza - Mestre e doutoranda em Política Social pela Universidade Federal Fluminense. Pesquisadora do LAPPDAR / UFVJM. E-mail: sidi.mara@hotmail.com

\section{Resumo}

Este artigo tem como objeto a inserção da população quilombola nas políticas definidas pelo Programa Nacional de Habitação Rural. Lançando mão de dados coletados em pesquisas recentes, discutimos as características das comunidades quilombolas que têm acessado a moradia por esta via. Os elementos que caracterizam a construção destas unidades habitacionais, são apresentados e avaliados a partir da relação com o desenho do Programa e com os gargalos operacionais que se impõem ao processo de implementação.

\begin{abstract}
This article has as its object the insertion of the population quilombola in the policies set by the National Program of Rural Housing. Using data collected in recent research, we discuss the characteristics of the quilombola communities that have accessed the dwelling this route. The elements that characterize the management of the processes of construction of these housing units, are presented and evaluated from the relation with the design of the Program and with the operational bottlenecks imposed on the implementation process.
\end{abstract}

\section{Palavras-chave}

Política Habitacional. Comunidades Quilombolas. Avaliação. Desenho de Programas.

\section{Keywords}

Housing Policy. Rural Communities. Evaluation. Program Design. 


\section{INTRODUÇÃO}

A política habitacional no Brasil se adensa na agenda pública no início da década de 1960, com a criação do Banco Nacional da Habitação. No entanto, o déficit habitacional e a não generalização de condições dignas de moradia são importantes fatores de desigualdade social e vulnerabilidade que persistem em alta proporção no país ainda hoje.

Segundo Maricato (2006), os estudos sobre carência de moradia e falta de condições dignas mostram que os déficits habitacionais estão concentrados nos extratos populacionais de baixa renda ( $92 \%$ dos casos), ou seja, famílias que recebem renda de até 5 salários mínimos. No entanto, destes $92 \%$, nada menos que $84 \%$ estão concentrados na faixa correspondente a até 3 salários mínimos de renda.

Outro fator relevante é a localização das moradias que não apresentam condições adequadas de habitabilidade, no geral construídas em áreas periféricas, de risco e insalubres (com carência de esgoto sanitário, contaminação da água e solo etc.). Não é ocioso enfatizar que a política implementada na década de 1960 também não levou em conta estes problemas e nem seguiu um planejamento que resultasse a inclusão das famílias em programas habitacionais seguros e de qualidade; bem como também não foi desenvolvido um planejamento financeiro adequado para atender a esta demanda.

Na década de 1980 o Banco Nacional da Habitação foi extinto e apenas na Constituição de 1988 o debate sobre a questão retorna com mais força a arena pública. Nesta carta constitucional, ficou estabelecido que através do processo de descentralização, a gestão da política habitacional seria de competência dos estados e municípios. No entanto, esta política só ganha espaço com a mobilização da sociedade civil, que passou a pressionar o Governo Federal a retomar a discussão sobre políticas públicas no Brasil em sua relação com o tema da inclusão social.

Em 2004, o Ministério das Cidades passou a implementar a Política Nacional de Habitação (PNH), proporcionando assim, de forma gradual, o enfrentamento do déficit neste campo da política social no Brasil. Estas ações tiveram como base estudos voltados para o diagnóstico e mapeamento de cada município, para subsidiar e garantir a mobilização de recursos e planejamento adequados à demanda existente.

A Política Nacional de Habitação (PNH) foi regulamentada pela Lei $\mathrm{n}^{\circ}$ 11.124/2005, que instituiu o Sistema Nacional de Habitação de Interesse Social e o Fundo Nacional de Habitação de Interesse Social (FNHIS). A partir daí, foi 
possível buscar uma maior aproximação com a demanda existente e trabalhar no sentido da inclusão de populações tradicionais, como indígenas e quilombolas. Mas este direcionamento havia começado um pouco antes, com a criação em 2003, do Programa Nacional de Habitação Rural (PNHR) que tem por objetivo reduzir os déficits habitacionais existentes nos territórios rurais. O Programa procurava oferecer acesso, com crédito muito facilitado, à financiamentos na área da habitação rural, para agricultores familiares em condição socioeconômica vulnerável.

A capilarização deste Programa somente iria ocorrer mais à frente. Especificamente, em 2007, a Lei no 11.1977, de 07 de julho, cria o Programa Minha Casa, Minha Vida (PMCMV), destinado ao incentivo à produção e aquisição de imóveis tanto urbanos, quanto rurais, para famílias com renda de até $\mathrm{R} \$ 4.650,00$. Já em 2009, uma Portaria Interministerial (nº 326, de 31 de agosto) dos Ministérios da Cidade e da Fazenda, localizam o Programa Nacional de Habitação Rural no âmbito do Programa Minha Casa, Minha Vida (vale ressaltar que somente em 2011, a Lei no 12.424 vai alterar a Lei de criação do PMCMV, para incluir o PNHR como um subprograma deste).

Com tais alterações, o Programa Nacional de Habitação Rural passa a corresponder a uma modalidade do Programa Minha Casa, Minha Vida, regulamentado pelo Ministério das Cidades. Seus objetivos se voltam para a população rural brasileira, atendendo agricultores familiares, trabalhadores rurais, assentados do Programa Nacional de Reforma Agrária e membros de comunidades tradicionais (quilombolas, extrativistas, pescadores artesanais, ribeirinhos, indígenas etc.).

O desenho do Programa indica possibilidades de financiamento diferentes para as regiões Nordeste, Centro-Oeste, Sudeste e Sul (onde a edificação da unidade habitacional é financiada até o limite de $\mathrm{R} \$ 28.500,00$ e a reforma até $\mathrm{R} \$ 17.200,00$ ) e para a região Norte (onde o a edificação da unidade habitacional é financiada até o limite de $\mathrm{R} \$ 30.500,00$ e a reforma até $\mathrm{R} \$ 18.400,00)$. Esta diferença seria explicada pelo "custo logístico" superior nesta última região.

São elegíveis famílias com até $\mathrm{R} \$ 60.000,00$ de renda anual bruta, mas somente aquelas com até $\mathrm{R} \$ 15.000,00$ (vale ressaltar que este é o caso absolutamente majoritário nas comunidades quilombolas) recebem o subsídio mais significativo e contribuem com somente $4 \%$ do valor inicialmente repassado para a construção ou reforma. Neste caso, o pagamento é dividido em quatro parcelas anuais, de valor igual, com a primeira devendo ser paga 12 meses após a assinatura do contrato. Ao contrário do que ocorre com o financiamento da habitação urbana, que é individualizado por unidade habitacional; no caso deste Programa Nacional de Habitação Rural o financiamento é coletivo, quando se trata de famílias com até $\mathrm{R} \$ 30.000,00$ de renda anual bruta. 
Aqui estamos em contato com certa "mística" - que parece mais advinda do senso comum do que de estudos científicos - que insiste em alocar as populações rurais no polo da Gemeinschaft (comunidade), enquanto que a população urbana estaria no pólo da Gesellschaft (sociedade). Esta oposição, que remonta a obra de um dos fundadores da sociologia como ciência, o alemão Ferdinand Tonnies, publicada em 1887, ainda reverbera hoje, quando são desenhadas políticas para populações rurais.

Isto porque, há uma insistência em tomar o rural como algo que teria uma "afinidade eletiva" com elementos comunitários, no sentido ainda próximo da definição de Tonnies, ou seja: aglomerados humanos caracterizados por relações mais íntimas, interiores e gregárias. Tal configuração estaria marcada por relações de parentela e amizade próxima, que tenderiam ao consenso e à possibilidade de entendimento, convivência e por decorrência, vida em comum (TONNIES, 1947 p. 41). No polo oposto disto, teríamos a articulação societária onde as diferenças interpessoais tenderiam a gerar autonomia individual e, por conseguinte, uma permanente tensão com o coletivo.

Está ainda para ser feito um amplo estudo acerca da história da disseminação deste modelo teórico nas formas de pensar o mundo rural e o mundo urbano no Brasil. O fato é que, como um espectro, implícito ou explicito, esta oposição entre Gemeinschaft e Gesellschaft se faz notar ${ }^{1}$ em nossas políticas públicas.

Assim, os beneficiários deste Programa Nacional de Habitação Rural que possuem renda de até $\mathrm{R} \$ 30.000,00$ são atendidos em grupos de no mínimo 4 e no máximo 50 famílias. Estes precisam estar aglutinados em uma "entidade organizadora". Tal entidade pode ter caráter público (prefeituras, por exemplo) ou privado. Neste último caso o desenho do Programa aponta para as entidades representativas dos segmentos comunitários (obviamente sem fins lucrativos), tais como associações comunitárias, sindicatos de trabalhadores rurais, cooperativas de produtores etc.

\footnotetext{
No caso dos quilombolas o peso desta oposição é óbvio. Desde as primeiras titulações de territórios quilombolas, realizadas em 1995, os títulos de propriedade da terra foram de natureza coletiva e emitidos em nome de associações comunitárias. Em 2001, o Decreto 3.912 regulamenta este formato para as titulações, o que será mantido pelo Decreto 4.887/2003 que revoga o 3.912. No entanto, pesquisas que vêm sendo realizadas junto a comunidades quilombolas nos últimos anos, mostram que apesar destas imposições legais o quadro encontrado é distinto. Em 2011 uma pesquisa com lideranças comunitárias de 161 comunidades quilombolas que já estavam com o título de propriedade coletiva da terra emitido, encontrou em somente 14,9\% destas, iniciativas de produção agrícola coletiva (BRANDÃO; DA DALT; JORGE, 2015). Em estudo anterior, realizado com aproximadamente 150 comunidades quilombolas tituladas e não tituladas (BRANDÃO; DA DALT; GOUVEA, 2010), já apontavam que atividades de produção agrícola coletivas são desenvolvidas por uma parcela pequena das comunidades quilombolas brasileiras (o que de resto é uma característica do conjunto do campesinato brasileiro), pois o amplo predomínio entre estas é da produção familiar.
} 
A construção ou reforma destas unidades habitacionais deve utilizar um único regime de execução (acentuando, mais uma vez o caráter coletivo da produção do bem social que é alvo do Programa). O desenho proposto admite quatro possibilidades, das quais uma deve ser elegida.

A primeira seria o "mutirão assistido", onde os beneficiários produzem ou reformam em conjunto as unidades habitacionais, tendo apoio de assistência técnica especializada (engenheiro, mestre de obras, pedreiro, eletricista etc.). A segunda corresponde a "autoconstrução assistida", na qual o próprio beneficiário realiza a construção ou reforma, mais uma vez com auxílio de assistência técnica especializada. A terceira opção corresponde a "administração direta". Neste regime, a "Entidade Organizadora" fica responsável pela execução das obras e pode utilizar mão-de-obra do seu quadro de funcionários (quando houver) ou vinculada a ela (no caso de associações representativas de comunidades tradicionais, isso significa que os moradores podem ser captados para a tarefa). Por fim, há ainda a opção pela "empreitada global", onde uma construtora especializada é contratada para a execução da obra ou dos serviços de reforma, sendo previamente definido o valor e o tempo para finalização.

No caso das comunidades quilombolas, que pleiteiam acesso ao Programa, estas devem possuir o certificado de reconhecimento emitido pela Fundação Cultural Palmares (FCP). Também para estas, não impera o mesmo limite de até 4 módulos fiscais, por família, para acesso ao PNHR, uma vez que o título de terra das comunidades quilombolas, como já apontamos antes, é de natureza coletiva, por força da legislação vigente.

\section{MAS O QUE SÃO COMUNIDADES QUILOMBOLAS?}

Segundo informações da Secretaria Especial de Políticas de Promoção da Igualdade Racial (SEPPIR), a Fundação Cultural Palmares havia emitido até 2012, a certificação como "Quilombola” para 2.040 comunidades, 63\% destas situadas no Nordeste do país (SEPPIR, 2012). Apesar desta proporção de comunidades, a invisibilidade social constitui uma marca que historicamente vem atingindo estas populações em todo o país (REIS; GOMES, 1996). Por conta desta invisibilidade, os processos de vulnerabilização social são sobre determinados por ações de preconceito e discriminação de origem social e racial. Contra esse processo, o Governo Brasileiro vem tomando, desde 2003, tais comunidades como alvo de ações públicas.

De fato, a problemática relativa às comunidades quilombolas aparece na agenda das políticas públicas brasileiras a partir de 1988, mais especificamente 
quando estas são nomeadas (e, portanto, começam a ganhar alguma visibilidade) em dois momentos da Constituição Federal, a saber:

a) no artigo 216, $\int 5^{\circ}$ : "Ficam tombados todos os documentos e os sítios detentores de reminiscências históricas dos antigos quilombos" e;

b) no artigo 68 do Ato das Disposições Transitórias: “Aos remanescentes de quilombos que estejam ocupando suas terras é reconhecida a propriedade definitiva, devendo o estado emitir-lhes os títulos definitivos".

As comunidades remanescentes de quilombos se caracterizam pela organização em torno de uma identidade étnica diferenciada, além de dependerem de seus territórios para a viabilização de sua reprodução física, social, econômica e cultural. Sabemos que nas últimas décadas as discussões públicas e as ações políticas ancoradas em perspectivas tipicamente multiculturais têm invadido a cena pública brasileira. Neste campo, as questões relacionadas às relações raciais e aos problemas advindos das desigualdades entre os grupos de cor ou raça se destacam.

Ainda não foi feito um inventário preciso dos bastidores da formulação do tão conhecido artigo 68 dos Atos das Disposições Transitórias da Carta Constitucional de 1988. Seja como for, ali se nomeavam e se atribuíam direitos a um heterogêneo conjunto de comunidades de predominância negra que, salvo raras exceções, ainda não se pensavam como "remanescentes das comunidades dos quilombos" (JORGE, 2016).

$\mathrm{Na}$ Constituição de 1988, não se tratava de disponibilizar direitos para "quilombos", mas para populações negras (naquele momento pensadas como exclusivamente rurais) que tinham uma descendência em antigas comunidades quilombolas. Por outro lado, a definição e a própria imagem de quilombo subjacente, seja ao texto constitucional, seja ao próprio senso comum nacional do momento, ligava tais comunidades a ocorrências de fugas de escravos e constituição a partir daí de comunidades isoladas que resistiam a ações de recaptura. Para a grande maioria dos brasileiros, naquele ano de 1988 a representação do termo "quilombo" estava ainda ancorada em Palmares e seu grande herói Zumbi - tratava-se, portanto, muito mais de um estereótipo do que de uma leitura empírica da realidade destas populações.

No processo de operacionalização do Artigo 68, a dificuldade de produção de direitos à posse da terra para os "remanescentes das comunidades dos quilombos" ficou transparente por conta de dois aspectos: a) as comunidades negras rurais (e depois também urbanas) existentes no Brasil não são homogêneas entre si; e b) estas não constituem "fósseis arqueológicos" passíveis de serem submetidos a testes precisos de medição para atestar a veracidade de sua origem. 
Do difícil diálogo entre os agentes públicos e da intensa pressão do movimento negro e do nascente movimento quilombola, resultou uma progressiva modificação na forma de interpretar o que seriam os "quilombolas". Neste novo formato, a vinculação das comunidades com um passado de fuga da escravidão passa a ser somente um dos elementos a serem considerados neste processo de garantia de direitos. De fato, independente da forma como foi construída a comunidade (fuga, ocupação de territórios sem proprietários, ocupações de territórios abandonados pelos antigos proprietários, heranças, doações, migrações etc.), o importante passa a ser a existência de uma continuada reprodução material e cultural. É nesta direção, portanto, que a legislação começa a interpretar de forma diferenciada o termo "remanescentes das comunidades dos quilombos".

Assim, o decreto número 4.887, de 20 de novembro de 2003, em seu artigo $2^{\circ}$ considera:

Remanescentes das comunidades dos quilombos os grupos étnicoraciais, segundo critérios de auto atribuição, com trajetória histórica própria, dotados de relações territoriais específicas, com presunção de ancestralidade negra relacionada com a resistência à opressão histórica sofrida.

Parágrafo $1^{\circ}$. Para os fins deste Decreto, a caracterização dos remanescentes das comunidades dos quilombos será atestada mediante auto definição da própria comunidade.

Parágrafo $2^{\circ}$. São terras ocupadas por remanescentes das comunidades dos quilombos as utilizadas para a garantia de sua reprodução física, social e cultural.

Já no que tange às políticas sociais voltadas para esta população específica, em 2004 o Governo Federal lançou, por meio da SEPPIR, o Programa Brasil Quilombola. No desenho deste programa, fica claro que outros órgãos componentes do Estado também aderiram a interpretações mais ampliada do que seriam os "remanescentes dos quilombos".

Assim, o Programa Brasil Quilombola caracteriza-os como um "grupo étnico". Vemos referências implícitas a Weber (2011) no seu conhecido capítulo sobre relações étnicas e raciais, a Barth (2000) e a Castells (1999), quando o documento marca o caráter de autodefinição da etnia e da identidade, que teriam como matérias-primas possíveis tanto uma "ancestralidade comum", quanto "formas de organização política e social" e ainda "elementos linguísticos e religiosos". A partir deste pressuposto, o que singularizaria as comunidades quilombolas e atestaria uma proximidade entre os quilombos do passado e os quilombos atuais seria um conjunto de práticas sociais e econômicas, que envolvem o uso comum da terra (SEPPIR, Programa Brasil Quilombola: 10). 
A partir de pesquisas de amplo escopo realizadas em 2006, 2008 e 2011 junto a comunidades quilombolas de todas as regiões do país Brandão, Da Dalt e Gouvea (2010) e Brandão, Da Dalt e Jorge (2015), apontam que tais comunidades possuiriam, na atualidade, as seguintes características gerais (o que obviamente não anula a existência de características mais específicas):

a) Se localizam em áreas rurais, embora encontremos também algumas poucas comunidades urbanas no Brasil (seja em metrópoles - como a Família Silva em Porto Alegre-RS - seja como bairros situados na área urbana de municípios mais tipicamente rurais - como a comunidade de Bairro Novo em Penalva-MA).

b) Ampla maioria dos responsáveis pelos domicílios trabalha em atividades agrícolas, principalmente na qualidade de agricultores de subsistência - embora encontremos também trabalhadores rurais autônomos e assalariados rurais (em pequena quantidade). A presença de chefes de domicílios ocupados com atividades urbanas é ínfima entre os quilombolas do país.

c) As comunidades quilombolas compõem o pequeno campesinato, que sobrevive da produção descapitalizada e em pequena escala, de insumos agrícolas (e em poucos casos agropecuários), que são consumidos pelo núcleo familiar e comercializados de forma esporádica quando há excedente e quando existe mercado de consumo.

d) As situações de produção econômica coletiva são pouco frequentes entre os quilombolas. De forma semelhante ao conjunto do campesinato pobre típico do Brasil, vemos entre estas amplo predomínio da produção agrícola familiar, com raras iniciativas de produção coletiva ou comunitária.

f) Os quilombolas em geral possuem baixa escolaridade. Entre os responsáveis pelos domicílios encontramos uma majoritária parcela de indivíduos que chegam somente a quatro anos completos de estudos.

g) A renda das famílias é, em média, muito baixa.

h) No que tange às creches, a cobertura nas comunidades quilombolas é pequena, pois o percentual de crianças de até 04 anos inseridas nestes espaços é praticamente nulo. Já no campo da educação básica a cobertura se mostra efetiva: entre os 5 e 19 anos de idade há um percentual sempre muito baixo de indivíduos que não frequentam a escola.

i) Encontramos entre os quilombolas um percentual pequeno, mas não insignificante, de crianças (de ambos os sexos) envolvidas com o trabalho na agricultura. 
j) A infraestrutura das comunidades está muito aquém do ideal. É quase inexistente a presença de redes de coleta de esgoto nestas comunidades.

h) Encontramos nas comunidades quilombolas uma situação de grande insegurança alimentar.

\section{COMO AS COMUNIDADES QUILOMBOLAS TÊM ACESSADO O PNHR}

As ações no campo da habitação junto às comunidades quilombolas estão relacionadas ao Programa Brasil Quilombola (PBQ), instituído a nível federal em 2004 e vigente até os dias atuais. Tal Programa contém um "EIXO 2: Infraestrutura e Qualidade de Vida" que prevê o desenvolvimento de políticas públicas federais nas áreas de habitação, saneamento, eletrificação, comunicação e vias de acesso.

Vale ressaltar que o Programa Brasil Quilombola foi criado com o objetivo de sistematizar e consolidar uma política de Estado de abrangência transversal para os territórios quilombolas. Do Programa derivou a Agenda Social Quilombola (Decreto nº 6261/2007), que agrupa as ações voltadas às comunidades em várias áreas. A coordenação geral do Programa é de responsabilidade da Secretaria Especial de Políticas para a Igualdade Racial, que atua em conjunto com os ministérios que compõem o seu Comitê Gestor.

O Programa Brasil Quilombola gerou um projeto piloto de construção de casas para famílias quilombolas na comunidade Kalunga, situada no estado de Goiás. Mas a inclusão das comunidades quilombolas nos programas habitacionais se verificou de forma mais sólida com a criação do já citado Programa Nacional de Habitação Rural, que se materializa como linha de financiamento do Programa Minha Casa, Minha Vida.

Por conta de um acordo de cooperação firmado em novembro de 2009 entre a SEPPIR e a Caixa Econômica Federal (CEF) as comunidades quilombolas passaram a ser priorizadas no processo de seleção dos projetos habitacionais. Nesta direção, segundo o último relatório do Programa Brasil Quilombola, datado de 2012 (SEPPIR, 2012), até 2011, cerca de 2.800 unidades habitacionais voltadas para este grupo foram construídas ou estavam com construção em vias de finalização. Havia a previsão naquele momento de que a partir de 2012 mais 2.049 casas fossem construídas.

Em pesquisa realizada no ano de 2011, junto a 161 comunidades quilombolas que já haviam obtido o título de propriedade coletiva dos seus territórios, foram encontradas 100 comunidades em que os moradores apontavam terem acessado 
ou estarem acessando programas habitacionais. Estas 100 comunidades estavam dispersas em 52 municípios, 23 situados na região Nordeste, 2 na região Sudeste, 2 na região Sul, 19 na região Nordeste e 6 na região Centro-Oeste. Destas 100 comunidades somente duas estavam localizadas em área urbana, exatamente as da Região Sul do país. Trata-se de comunidades com baixo número de habitações, uma situada em Porto Alegre-RS e outra em Canoas-RS.

Vejamos as características destes domicílios que acessaram algum programa habitacional. A primeira constatação importante diz respeito à generalização do fornecimento de energia elétrica no país na última década. Como vemos no Quadro 1, 90\% destas residências têm acesso a rede pública para iluminação interna.

Quadro 1 - Forma de iluminação da residência.

\begin{tabular}{|c|c|}
\hline Forma de iluminação & $\mathbf{\%}$ \\
\hline Elétrica (de rede, gerador, solar) & 90,5 \\
Óleo, querosene ou gás de botijão & 8,0 \\
Outra & 0,8 \\
Não tem & 0,4 \\
Total & 99,7 \\
NS/NR & 0,3 \\
\hline Total & 100,00 \\
\hline
\end{tabular}

Fonte: Tabulação própria a partir do banco de dados da pesquisa: Avaliação da Situação de Segurança Alimentar e Nutricional em Comunidades Quilombolas Tituladas (DATAUFF, 2012).

Já a situação referente ao destino do lixo é deficitária. Como vemos no Quadro 2, a coleta (direta ou indireta) é realizada somente em cerca de 10\% destes domicílios.

Quadro 2 - Destino do lixo residencial

\begin{tabular}{|l|r|}
\hline \multicolumn{1}{|c|}{ Destino do lixo } & \multicolumn{1}{c|}{$\%$} \\
\hline Coletado diretamente & 8,7 \\
\hline Coletado indiretamente & 1,6 \\
\hline Queimado ou enterrado na propriedade & 80,9 \\
\hline Jogado em terreno baldio ou logradouro & 8,3 \\
\hline Jogado em rio, lago ou mar & 0,4 \\
\hline Total & 99,8 \\
\hline NS/NR Total & 0,2 \\
\hline \multicolumn{1}{|c|}{ Tra } & 100,0 \\
\hline
\end{tabular}

Fonte: Tabulação própria a partir do banco de dados da pesquisa: Avaliação da Situação de Segurança Alimentar e Nutricional em Comunidades Quilombolas Tituladas (DATAUFF, 2012). 
Também é complexa a situação da infraestrutura quando tomamos como indicador o destino do esgoto sanitário nos domicílios que acessaram programas habitacionais. A rede pública chega a somente 9 destes. Mas, mesmo as soluções que poderiam ser mais aceitáveis em áreas rurais, têm baixa frequência. É o caso da fossa séptica ligada à rede coletora (que atinge 1,4\% destas residências) e da fossa séptica não ligada à rede (11,5\%). O predomínio absoluto é da fossa rudimentar (50,9\%), seguida pelo despejo à céu aberto ou em vala $(33,7 \%)$.

O potencial de contaminação de rios, nascentes e solos que tais resultados expressam é bastante preocupante.

Quadro 3 - Destino do esgoto sanitário

\begin{tabular}{|l|r|}
\hline \multicolumn{1}{|c|}{ Destino do esgoto } & \multicolumn{1}{c|}{$\%$} \\
\hline Rede pública coletora de esgoto ou pluvial & 0,2 \\
\hline Fossa séptica ligada à rede coletora de esgoto ou pluvial & 1,4 \\
\hline Fossa séptica não ligada à rede coletora de esgoto ou pluvial & 11,5 \\
\hline Fossa rudimentar (poço, buraco) & 50,9 \\
\hline Vala / céu aberto & 33,7 \\
\hline Direto para o rio, lago ou mar & 1,8 \\
\hline Total & 99,5 \\
\hline NS/NR & 0,5 \\
\hline \multicolumn{2}{|c|}{ Total } \\
\hline
\end{tabular}

Fonte: Tabulação própria a partir do banco de dados da Pesquisa Avaliação da Situação de Segurança Alimentar e Nutricional em Comunidades Quilombolas Tituladas (DATAUFF, 2012)

O acesso à água encanada também não é generalizado. Como vemos no Quadro 4, somente cerca de 42\% destes domicílios recebem água desta forma. É claro que formas alternativas de coleta de água tendem a gerar impactos negativos sobre a saúde das famílias.

Quadro 4 - Acesso à água encanada

\begin{tabular}{|c|c|}
\hline Água encanada & $\%$ \\
\hline Sim & 42,4 \\
\hline Não & 57,4 \\
\hline Total & 99,9 \\
\hline NS/NR & 0,1 \\
\hline Total & 100,0 \\
\hline
\end{tabular}

Fonte: Tabulação própria a partir do banco de dados da Pesquisa Avaliação da Situação de Segurança Alimentar e Nutricional em Comunidades Quilombolas Tituladas (DATAUFF, 2012) 
Neste campo do acesso à saúde, uma opção que vem sendo utilizada pelo governo federal desde os anos 1990, consiste na disseminação de Agentes Comunitários de Saúde (ACS), em geral coordenados por enfermeiros. Tais agentes atuam com ponta de lança de uma estratégia de saúde preventiva (de fato, estes ACSs estão inseridos no programa federal chamado Estratégia de Saúde da Família).

A presença deste serviço público entre as famílias que haviam acessado os programas habitacionais é elevada, mas não generalizada. Considerando que, em geral, existem precárias condições de acesso à saúde na zona rural do país, seria salutar encontrar uma maior cobertura por parte deste programa.

Quadro 5 - Famílias que são atendidas por Agente Comunitário de Saúde

\begin{tabular}{|l|r|}
\hline \multicolumn{1}{|c|}{ Atendidas por agente comunitário de saúde } & \multicolumn{1}{|c|}{$\mathbf{\%}$} \\
\hline Sim & 77,0 \\
\hline Não & 22,8 \\
\hline Total & 99,8 \\
\hline NS/NR & 100,0 \\
\hline \multicolumn{2}{c}{ Total } \\
\hline
\end{tabular}

Fonte: Tabulação própria a partir do banco de dados da pesquisa: Avaliação da Situação de Segurança Alimentar e Nutricional em Comunidades Quilombolas Tituladas (DATAUFF, 2012)

Quase 80\% destes domicílios são cobertos pelo Programa Bolsa Família (PBF). Esta taxa de acesso é um pouco maior entre estes e os que acessaram programas habitacionais, quando comparados com o conjunto dos domicílios investigados na pesquisa. Nestes últimos, o acesso ao PBF atinge 61\%, o que parece indicar que os programas habitacionais têm conseguido chegar a famílias quilombolas mais vulneráveis.

Quadro 6 - Acesso da família ao Programa Bolsa Família

\begin{tabular}{|c|c|}
\hline Acesso ao Programa Bolsa Família & $\%$ \\
\hline Sim & 79,0 \\
\hline Não & 20,7 \\
\hline Total & 99,8 \\
\hline $\mathrm{NS} / \mathrm{NR}$ & 0,2 \\
\hline Total & 100,0 \\
\hline
\end{tabular}

Fonte: Tabulação própria a partir do banco de dados da Pesquisa Avaliação da Situação de Segurança Alimentar e Nutricional em Comunidades Quilombolas Tituladas (DATAUFF, 2012) 
Esta afirmação relativa à vulnerabilidade das famílias se verifica também no Quadro 7 abaixo. Quando buscamos mapear a forma principal de obtenção de recursos financeiros das famílias, verificamos que mais de $61 \%$ destas não recebem recursos de fontes vinculadas à venda de produtos agropecuários, trabalho remunerado ou aposentadoria. Isto mostra que, como havíamos apontado anteriormente, tais comunidades em geral possuem produção agrícola, mas a mesma raramente chega ao mercado, sendo utilizada para o autoconsumo das famílias. Também o acesso ao trabalho remunerado é baixo (e predominante sob a forma de diária). Daí o elevado percentual de cobertura do Programa Bolsa Família.

Quadro 7 - Forma principal de obtenção de recursos financeiros da família nos últimos 12 meses antes da pesquisa

\begin{tabular}{|l|r|}
\hline \multicolumn{1}{|c|}{ Forma principal de obtenção de recursos financeiros } & \multicolumn{2}{c|}{$\%$} \\
\hline Venda do cultivo ou criação de animais & 9,6 \\
\hline Trabalho remunerado - ano todo & 3,9 \\
\hline Trabalho remunerado - temporário & 2,0 \\
\hline Trabalho remunerado - diarista & 7,7 \\
\hline Venda de artesanato ou produção cultural &, 4 \\
\hline Aposentadoria & 6,9 \\
\hline Nenhum & 61,4 \\
\hline NS/NR Total & 8,1 \\
\hline \multicolumn{2}{|c|}{ Tra } \\
\hline
\end{tabular}

Fonte: Tabulação própria a partir do banco de dados da Pesquisa Avaliação da Situação de Segurança Alimentar e Nutricional em Comunidades Quilombolas Tituladas (DATAUFF, 2012)

Como decorrência, a renda familiar per capita é muito baixa (vale ressaltar que consideramos para o cálculo desta, também o que a família recebe através de transferência de renda de programas sociais). Nada menos que metade destes domicílios alcança somente $\mathrm{R} \$ 70,00$ de renda per capita e estariam na faixa tipicamente considerada como de população miserável. Outros 21,8\% chegam a R \$ 139,99 de renda. Estes dados, mais uma vez apontam para uma situação de maior precariedade, quando comparados com aqueles extraídos do conjunto das 161 famílias que foram alvo da investigação (nestas, 45\% estavam na primeira faixa e $17,9 \%$ na segunda). 
Quadro 8 - Renda mensal domiciliar per capita

\begin{tabular}{|c|c|}
\hline Classe de renda mensal domiciliar per capita & $\%$ \\
\hline Menos de 70,00 & 50,3 \\
\hline 70,00 a 139,99 & 21,8 \\
\hline 140,00 a 254,99 & 17,4 \\
\hline 255,00 a 509,99 & 8,1 \\
\hline 510,00 ou mais & 2,4 \\
\hline Total & 100,0 \\
\hline
\end{tabular}

Fonte: Tabulação própria a partir do banco de dados da Pesquisa Avaliação da Situação de Segurança Alimentar e Nutricional em Comunidades Quilombolas Tituladas (DATAUFF, 2012)

$\mathrm{Na}$ pesquisa que deu origem aos dados aqui apresentados, foram coletadas informações para a composição da "Escala Brasileira de Insegurança Alimentar" (EBIA). Trata-se de um dos principais instrumentos de mensuração da situação de insegurança alimentar em uso no Brasil. A EBIA corresponde a uma escala composta por 15 perguntas que são lidas pausadamente para o responsável pela família, e que somente podem ser respondidas com as opções "sim" ou "não". Do escore obtido pelas respostas, são derivadas as quatro categorias que aparecem no Quadro 9.

Como vemos, entre as famílias que acessaram programas habitacionais a situação de "segurança alimentar" é rara, atingindo somente 10,1\% destas. Já a maior frequência está na "insegurança alimentar grave” (49,8\%), situação na qual a família já experimentou e/ou experimenta situações de fome. Mais uma vez, estas famílias encontram-se em situação ainda pior do que a encontrada entre as 161 comunidades pesquisadas (nas quais a "segurança alimentar" chegava a 14,1\% das famílias e a "Insegurança alimentar grave" atingia 47,5\%).

Quadro 9 - Disposição das famílias na Escala Brasileira de Insegurança Alimentar

\begin{tabular}{|l|r|}
\hline \multicolumn{1}{|c|}{ Categoria na EBIA } & \% \\
\hline Segurança Alimentar & 10,1 \\
\hline Insegurança Alimentar Leve & 14,7 \\
\hline Insegurança Alimentar Moderada & 24,4 \\
\hline Insegurança Alimentar. Grave & 49,8 \\
\hline NS/NR & 1,0 \\
\hline \multicolumn{2}{|c|}{ Total } \\
\hline
\end{tabular}

Fonte: Tabulação própria a partir do banco de dados da Pesquisa Avaliação da Situação de Segurança Alimentar e Nutricional em Comunidades Quilombolas Tituladas (DATAUFF, 2012) 
Este conjunto de problemas identificados acima, apontam para tensões que atravessam a formulação e implementação de programas públicos que se voltam para os segmentos mais pobres e vulneráveis da população. Ainda que seja necessário frisar que somente agora, no século XXI, políticas habitacionais chegaram às comunidades tradicionais brasileiras, os resultados ainda estão muito aquém do que deveríamos esperar quando temos como horizonte a garantia de níveis mínimos de bem-estar.

Aqui cabe uma reflexão acerca da própria dinâmica que atravessa o binômio formulação-implementação de políticas sociais (ARRETCHE, 2001). Vamos nos deter em somente dois elementos, que podem nos ajudar a entender os déficits que cercam os domicílios quilombolas que acessaram programas habitacionais.

O primeiro elemento diz respeito à necessária existência de uma "entidade organizadora" para aglutinar as famílias (entre 4 e 50, como vimos), que estão pleiteando acesso ao Programa Nacional de Habitação Rural. Tal entidade deve ser sempre sem fins lucrativos, mas pode pertencer tanto à esfera pública (prefeituras, por exemplo), quanto a esfera privada (associações comunitárias, por exemplo). No caso das comunidades quilombolas, suas entidades de representação são as "associações quilombolas" ou "associação comunitárias", que, pelo menos formalmente devem ter existência, uma vez que o título coletivo de propriedade da terra é emitido em nome desta.

Nos dois casos é necessário nos perguntarmos acerca da capacidade de gestão da "entidade organizadora", frente às tarefas pelas quais deve ser responsável. Isto porque a lista de "atribuições" é enorme e inclui não somente o levantamento da documentação das famílias que serão beneficiadas, mas também a articulação de pessoal técnico para produzir projetos de engenharia e arquitetura; a organização das famílias em torno da construção da proposta mais geral de habitação rural; o acompanhamento através dos técnicos da execução das obras, etc.

Parece bastante evidente, que dificilmente uma associação quilombola possuirá a estrutura e mesmo a capacidade de gestão para desempenhar tais atribuições. Mesmo as prefeituras municipais de grande parte do mundo rural brasileiro não apresentam tal estrutura de recursos humanos ou se os possuem, isto se dá sempre na tangente da carência ou rotatividade de profissionais. Vemos aqui um exemplo, de um desenho de Programa caracterizado pelo conhecimento impreciso das características dos beneficiários e dos agentes que podem atuar em conjunto com estes.

Mais especificamente, no mundo perfeito do desenho do Programa, a prefeitura municipal poderia ceder um engenheiro de sua hipotética Secretária 
de Obras para - em conjunto com um hipotético sociólogo lotado na secretaria de agricultura - atuar na comunidade, produzir a proposta de habitação rural, construir plantas, gerenciar e fiscalizar as obras, etc. O problema é que este mundo ideal raramente vai ser encontrado na realidade brasileira.

Assim, o desenho do programa, tal como definido pelos seus formuladores, dificilmente poderá ser implementado da forma prevista. Isto porque, como nos lembra Arretche (2001), a forma que o programa adquire, quando colocado em funcionamento, depende das possibilidades dos implementadores, que em geral carregam limitações que são desconhecidas do formulador.

No caso em tela, é possível supor que o "pessoal técnico" previsto no desenho da Política Nacional de Habitação Rural, que deve ser articulado pela "entidade organizadora", será de fato, um funcionário da prefeitura, ou membro de uma ONG, que despenderá o tempo que lhe for possível, para atuar no processo. Mas deste técnico, dificilmente se poderá cobrar exclusividade, ou mesmo um nível maior de comprometimento.

O segundo elemento que queremos problematizar corresponde ao que o Programa Nacional de Habitação Rural define como o "regime construtivo das moradias rurais". As famílias agrupadas em torno da "entidade organizadora" devem optar por uma das quatro formas já descritas em item anterior. São estes:

- o "mutirão assistido", no qual os moradores vão produzir em conjunto as moradias ou reformas com o assessoramento técnico necessário;

- a "autoconstrução assistida", onde cada morador constrói sua própria unidade, mais uma vez com o apoio da assistência técnica;

- a "administração direta", em que será a "entidade organizadora" que executará a obra e;

- a "empreitada global”, regime em que é contratada uma construtora para a execução da obra, sendo fiscalizada por uma "comissão de representantes", eleitos em assembleia entre as famílias beneficiárias.

Nas quatro possibilidades listadas acima é possível intuir problemas de adequação entre o desenho do Programa e as limitações da implementação. Vejamos. Seja no "mutirão assistido" ou na "autoconstrução assistida", sobressai a demanda pela "assistência técnica”, em geral escassa nas áreas rurais e de baixa presença nas equipes das prefeituras municipais - questão já levantada por nós quando discutíamos as atribuições das "entidades organizadoras".

No que tange ao "mutirão assistido", ainda devemos ressaltar, que este formato de atuação produtiva coletiva, dificilmente é encontrado em comunidades "quilombolas", apesar do território destas receber titulação conjunta pro indiviso. Pesquisas realizadas indicam que os formatos de produção 
familiar e o sentimento de posse individual da moradia são quase generalizados entre as inúmeras comunidades que foram alvo de investigações sociológicas recentes (BRANDÃO; JORGE; DA DALT, 2016; BRANDÃO; DA DALT; GOUVEA 2010). O formulador do Programa parece ter operado aqui com a noção de Gemeinschaft (TONNIES, 1947), que parece informar certa leitura da população rural brasileira e mais do que isso, parece orientar a expectativa que várias políticas sociais atuais possuem em relação às respostas dos seus possíveis beneficiários. $^{2}$

No caso da "administração direta", fica evidente que a "entidade organizadora" - seja esta a própria "associação quilombola" ou mesmo a prefeitura municipal - precisará de um prévio acúmulo de experiência na área da construção ou reforma de moradias, para se desembaraçar a contento desta tarefa. Além do fato de que, uma ou outra, ainda dependerão da escassa possibilidade de obtenção de uma "assistência técnica" dedicada.

Por fim, a "empreitada global" implica em dois aspectos complexos. O primeiro se refere ao capital social e a confiança intersubjetiva (PUTNAM, 2007) que o desenho do Programa espera da comunidade, quando se refere a uma "comissão de representantes". Esta deveria ter a capacidade de sintetizar as aspirações, perspectivas e demandas do conjunto das famílias beneficiárias em torno da fiscalização da execução das obras, no sentido de atender a um projeto coletivo. O problema é que estes elementos que correspondem ao que a literatura da ciência política nomeia como "capital social" são bens de relativa raridade em sociedades com baixo grau de associativismo, como a brasileira.

Neste ponto, a baixa frequência de experiências de atuação econômica coletiva entre as comunidades quilombolas impõe uma dificuldade para a implementação. Mais uma vez, se pensarmos no "mundo perfeito" do desenho do Programa, estaremos esperando comunidades com alto nível de organização interna, com ampla confiança intersubjetiva e grande quantidade de capital social acumulado. Nestas, eleger uma "comissão de representantes", que se manterá completamente vinculada ao tecido social local e será a "expressão" da comunidade, é algo relativamente simples. Mas tal configuração não é encontrada com facilidade nas comunidades.

\footnotetext{
Um exemplo disto encontramos no Programa de Aquisição de Alimentos (PAA). Este possibilita a compra de insumos agropecuários produzidos pela agricultura familiar à preços de mercado. O Programa acaba gerando o que podemos chamar de um mercado institucional, bastante importante, seja para liberar os agricultores familiares da figura do atravessador, seja para evitar perda da produção em momentos de baixa demanda. No entanto, o acesso ao PAA não se faz pelo agricultor individual, mas sim por uma associação que aglutine este e os represente. Assim, a pressuposição de um caráter coletivo ou de uma predisposição associativa, marca o desenho do Programa.
} 
O segundo aspecto diz respeito à própria capacidade técnica que esta comissão terá para realizar a requerida "fiscalização". E aqui retornamos ao problema da escassez de pessoal técnico especializado nas prefeituras municipais.

Quando o desenho proposto pelo Programa não se adéqua às características dos seus futuros beneficiários, ou quando não existem as condições institucionais (de ordem material ou política) para que seja seguido o que fora inicialmente definido; os implementadores são levados a "improvisar" (ARRETCHE, 2001). Ou seja, o caminho possível é o da adaptação do desenho às possibilidades e características concretas das realidades onde a intervenção está sendo efetivada.

Como lembrar Arretche (2001), quem faz a política, de fato, não é o formulador desta, mas sim aqueles que a implementam. Estes, em geral agentes localizados em estruturas de gestão simplificadas, são pagos para que os programas sejam implementados, têm, portanto, problemas concretos para resolver. Não podem contar nem com os recursos que jamais poderão obter, nem com expectativas pressupostas de como os beneficiários vão responder às políticas.

\section{CONCLUSÃO}

Como já apontamos, constitui um indicador da baixa densidade de nosso aparato de políticas sociais, o fato de somente na primeira década do século XXI, o Estado brasileiro ter iniciado a produção de uma estrutura voltada para a questão habitacional relativa às nossas populações quilombolas.

Foram necessários quase 100 anos de regime republicano para que estes grupos entrassem na agenda do Estado. Mas tal entrada não gerou rapidez na incorporação ou na extensão da cobertura estatal. Um exemplo, encontra-se no fato de que, ainda que somente com a Constituição de 1988 estes grupos - até então pensados como "comunidades negras rurais" - sejam reconhecidos e recebam a garantia da propriedade definitiva de seus territórios ancestrais; somente em 1995 ocorre a primeira titulação de um destes (trata-se da comunidade de Boa vista, situada na área de floresta do município de Oriximiná-PA).

Nesta direção, o processo de regularização da situação fundiária dos quilombolas continua caminhando a passos lentos. Tínhamos até 2012, nada menos que 2.040 comunidades com certificação emitida pela Fundação Cultural Palmares, mas somente 207 comunidades tituladas. Fazendo um cálculo rápido, vemos que o ritmo médio é de 8,6 comunidades tituladas por ano. Caso este ritmo seja mantido, serão necessários 213 anos para que todas recebam a titulação territorial definitiva. 
Por outro lado, apesar de existirem esforços públicos na esfera federal para incrementar o acesso destas populações às políticas sociais e assistências, ainda encontramos entre estas, índices muito baixos de bem-estar material e de desenvolvimento socioeconômico, como mostramos antes.

$\mathrm{O}$ acesso à política habitacional por parte destes grupos constitui de fato uma novidade no panorama brasileiro. Mas este acesso carrega as marcas de certa improvisação ou da necessidade de realizar o que for possível, deixando de lado protocolos fundamentais para o bem-estar das famílias e mesmo para a saúde das comunidades (como aqueles ligados à qualidade mínima das unidades habitacionais, ao abastecimento de água, à coleta de esgoto e ao destino do lixo doméstico).

Nesta área onde o Estado brasileiro acaba de entrar e na qual possui baixo acúmulo de experiências de formulação e implementação, o avanço possível demanda iniciativas públicas - mas independentes - de avaliação destes programas habitacionais voltados para áreas rurais e para populações tradicionais como os quilombolas. Isto porque, avaliações cientificamente construídas - voltadas não somente para apontar se o Programa "acertou" ou "errou" podem mapear e identificar pontos de estrangulamento, que fazem com que os objetivos desenhados não sejam alcançados ou que os objetivos mesmo quando alcançados, não produzam impactos.

Este tipo de investigação, ao eleger como pano de fundo principal as características dos grupos beneficiários, pode subsidiar alterações e correções de rota. Isto é fundamental para que no futuro, encontremos maior grau de eficácia e efetividade nas ações públicas que envolvem o bem-estar social de grupos populacionais que foram historicamente discriminados e mesmo invisibilizados pela sociedade envolvente e pelo Estado.

\section{REFERÊNCIAS}

ARRETCHE, Marta. Uma contribuição para fazermos avaliações menos ingênuas. In: BARREIRA, Maria Cecília; CARVALHO, Maria do Carmo Brant de (Org.). Tendências e perspectivas na avaliação de políticas e programas sociais. São Paulo: PUC-SP, 2001.

BARTH, Fredrik. Os grupos étnicos e suas fronteiras. In: BARTH, Fredrik. O guru, o iniciador e outras variações antropológicas. Rio de Janeiro: Contracapa. 2000.

BRANDÃO, André; DA DALT, Salete; GOUVEIA, Vitor. Comunidades 
quilombolas no Brasil: características socioeconômicas, processos de etnogênese e políticas sociais. Niterói-RJ: EDUFF, 2010.

BRANDÃO, André; DA DALT, Salete; JORGE, Amanda L. Avaliação da situação socioeconômica das comunidades quilombolas já tituladas: crônica de um mau resultado anunciado. Trabalho apresentado no XVII Congresso Brasileiro de Sociologia, Porto Alegre, 2015.

BRANDÃO, André; JORGE, Amanda L.; DA DALT, Salete. Faz diferença estar na agenda: Lideranças comunitárias quilombolas e percepções sobre acesso às políticas sociais nos anos recentes. Trabalho apresentado na $40^{\mathrm{a}}$ Reunião Anual da ANPOCS, Caxambu, 2016.

CASTELLS, Manuel. O poder da identidade. São Paulo: Paz e Terra, 1999.

IBGE. Síntese de Indicadores Sociais. Rio de Janeiro, 2012.

JORGE, Amanda L. O processo de construção da questão quilombola: discursos em disputa. Rio de Janeiro, Gramma, 2016.

MARICATO, Ermínia. O Ministério das Cidades e a política nacional de desenvolvimento urbano. In: IPEA. Políticas sociais - acompanhamento e análise. Brasília, fev. 2006.

PUTNAN, Robert. Comunidade e democracia. Rio de Janeiro: FGV, 2007.

REIS, João José e GOMES, Flávio. Liberdade por um fio: história dos quilombos no Brasil. São Paulo: Companhia das Letras, 1996.

SEPPIR. Programa Brasil Quilombola: relatório de gestão. Brasília, 2012. Programa Brasil Quilombola. Brasília, 2004.

TÖNNIES, Ferdinand. Comunidad y sociedad. Buenos Aires: Losada, 1947.

WEBER, Max. Economia e sociedade. Brasília: UNB, 2011. (2 volumes) 